\title{
Origen y construcción de la Penitenciaria del Estado de Cundinamarca en la Provincia de Bogotá (1849-1872)
}

\author{
Origin and construction of the Penitentiary of the State of Cundinamarca in the \\ Province of Bogotá (1849-1872) \\ Origem e construção da Penitenciária do Estado de Cundinamarca na \\ Província de Bogotá (1849-1872)
}

José Alexander Pinzón Rivera. M.Sc.

alexpin2006@yahoo.es

(iD) https://orcid.org/0000-0003-0848-9712

Recibido: Mayo 5 de 2018

Universidad Nacional de Colombia.

Aceptado: Septiembre 4 de 2018

Magister en Historia y Teoría del Arte, la Arquitectura y la Ciudad.

Publicado: Diciembre de 2018

\section{RESUMEN}

El presente artículo da cuenta de los principales factores que dieron origen al proyecto para la penitenciaria de Bogotá. Para responder a esto, se localizaron los informes de la época, mapas originales de los arquitectos, solares y reconstrucciones planimétricas de los espacios que conformaron la prisión. La metodología empleada es de tipo cualitativa en cuanto al estudio de la información recuperada, y cuantificada en relación a los materiales y técnicas entonces empleadas. Los resultados apuntan a la identificación de los lugares del proceso constructivo y la narración de los hechos entre la concepción del edificio en 1849 y los inicios de la fábrica en 1872.

Palabras clave: arquitectura penitenciaria; Thomas Reed; Museo Nacional de Colombia.

\section{ABSTRACT}

This article gives an account of the main factors that gave rise to the project for the Bogota penitentiary. To respond to this, the reports of the time, original maps of the architects, plots and planimetric reconstructions of the spaces that formed the prison were located. The methodology used is qualitative in terms of the study of the information recovered, and quantified in relation to the materials and techniques then used. The results point to the identification of the places of the construction process and the narration of the facts between the conception of the building in 1849 and the beginning of the factory in 1872.

Keywords: penitentiary architecture; Thomas Reed; National Museum of Colombia.

\section{RESUMO}

Este artigo dá conta dos principais fatores que deram origem ao projeto da penitenciária de Bogotá. Para responder a isso, foram localizados os relatórios da época, mapas originais dos arquitetos, parcelas e reconstruções planimétricas dos espaços que formaram a prisão. A metodologia utilizada é qualitativa em termos do estudo da informação recuperada e quantificada em relação aos materiais e técnicas então utilizados. Os resultados apontam para a identificação dos locais do processo de construção e a narração dos fatos entre a concepção do edifício em 1849 e o início da fábrica em 1872.

Palavras-chave: arquitetura penitenciária; Thomas Reed; Museu Nacional da Colômbia.

Como citar (APA)

Pinzón Rivera, J. (2018). Origen y construcción de la Penitenciaria del Estado de Cundinamarca en la Provincia de Bogotá (1849-1872). Procesos Urbanos. 5:3-16. https://doi.org/10.21892/2422085X.403 


\section{Introducción}

A decir del investigador Sergio García Ramírez, existen temas que siempre están entre nosotros, nos acompañan, entre ellos, el crimen y el castigo. Para quienes cometen un delito o infringen las leyes de una sociedad, se han creado infinidad de castigos, por ejemplo, la privación de la libertad o la pena de muerte. $Y$, en ocasiones, es la prisión el lugar al que es conducido quien ha cometido un delito (García, 2003: 7-8). En la sociedad bogotana del siglo XIX, los problemas sobre el mal estado de las cárceles de hombres y mujeres en hacinamiento decantaron en la idea progresista de crear un espacio amplio que reemplazará algunas de las reducidas, antiguas e improvisadas cárceles del periodo colonial. Para dar solución a esta problemática, se proyectó la Penitenciaria del Estado de Cundinamarca a cargo del arquitecto Reed (ver Figura 1), quien, influenciado por las experiencias europeas en materia de diseño y construcción de prisiones, proyectó en la ciudad una de las principales edilicias de castigo en el territorio neogranadino. A partir de estos preceptos, el presente artículo responde a dos interrogantes principales: ¿Cuál fue el origen y la evolución constructiva de la penitenciaria para la Provincia de Bogotá? ¿Cuáles fueron los espacios y usos del edificio?

El proyecto original para la Penitenciaria del Estado de Cundinamarca, en Bogotá, fue trazado en 1849 por el arquitecto inglés Thomas Reed (1817-1878) (Saldarriaga, Ortiz Pinzón, 2005: 19-20). Se sabe que Reed se formó como arquitecto e ingeniero en una academia europea, siendo factible que viajara hacía 1835 desde la Isla de Saint Croix, en el Caribe, hasta Alemania e Inglaterra, donde es probable que se convirtiera en alumno del arquitecto alemán Karl Friedrich Schinkel, en la Academia de Arquitectura de Berlín (Bauhouse Academie o Berliner Bauakademie) entre 1835 y 1840, entre los 18 y 23 años de edad. Reed regresó al Caribe, a la Isla de Santa Cruz-donde residía su padre, John N. Reed-y trabajó en algunas labores relacionadas con la arquitectura a pequeña escala en Mayagüez, Puerto Rico y la Isla de Santa Cruz. Posteriormente, en 1843, se desplazó al Puerto de la Guaira y de allí a la ciudad de Caracas, donde ofreció sus servicios como arquitecto, realizando los planos de un teatro de planta de herradura de estilo neoclásico, para erigir en la Plaza de San Pablo. Teatro que nunca se construyó, quedando el proyecto trazado en una plancha metálica de cobre que data de 1844 y convirtiéndose en la primera litografía realizada en territorio venezolano. Al año siguiente, en el puerto de la Guaira, Reed diseñaría la primera de sus tres penitenciarias erigidas en Suramérica: "un edificio pabellonar, con dos alas de dos niveles que fue terminado en 1857" (García Básalo, 2016: 129-130). Hoy se conoce que en 1950 se demolió esta edificación - llamada también "Cárcel Pública"-, con el objeto de dar paso a la avenida que comunica el aeropuerto de Maiquetía con el resto del litoral venezolano (Saldarriaga, Ortiz, Pinzón, 2005: 74).

Manuel Ancízar Basterra -Ministro Plenipotenciario durante la primera administración presidencial del general Tomás Cipriano de Mosquera (ver Figura 2)- contactó en 1846, en Caracas, al joven arquitecto Reed (quien contaba con 29 años) para proponerle la proyección de un palacio de gobierno (o capitolio) para la capital de la Nueva Granada. Reed aceptó trazar los planos del proyecto y redactó las especificaciones técnicas y conceptuales del emblemático edificio. En consecuencia, viajó en septiembre de 1846 desde Caracas a Bogotá, siguiendo, probablemente, la ruta Maracaibo-Cúcuta-provincias de Santander y, finalmente, Bogotá. A su arribo, a finales del mismo año, se dedicó también a impartir una cátedra de arquitectura a los estudiantes de la Universidad Central.
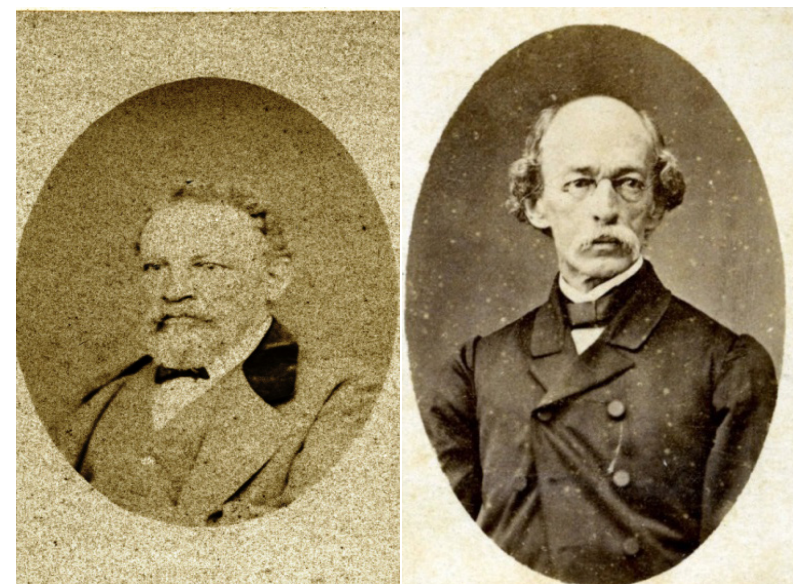

Figura 1. Thomas Reed, Quito 1872. Figura 2. Manuel Ancizar (1812-1882). Tarjeta de visita. Como recuerdo de amistad (arquitecto), Vargas, Pedro José (Fotógrafo).

Fuente: Instituto Metropolitano de Patrimonio de Ecuador. Precedencia: Colección Alphons Stübel. Código: 6061. Fotografía suministrada por Alfonso Ortiz Crespo. Fuente electrónica: https://www.flickr.com/photos/banrepcultural/2784324363/

Antes del trazado de los planos para una penitenciaria en Bogotá, Reed había trabajado en los cimientos, zócalo y terraplén del Capitolio; un Salón para la Cámara de Representantes en 1847 y la Sede para la Sociedad Filarmónica, en 1848, de la cual también fue miembro fundador desempeñándose como músico, interpretando el arco de violín. Igualmente, trabajó como profesor de Arquitectura en el Colegio Militar, donde tuvo como discípulos a Ramón Guerra Azuola -quien 27 años más tarde se convertiría en el arquitecto que daría continuidad al proyecto original de la Penitenciaria del Estado de Cundinamarca-.

Se desconoce exactamente el momento de partida de Reed hacía el Perú, aunque algunos autores como Gustavo Arboleda, sugieren que abandonó la República de la Nueva Granada el 12 de enero de 1860 (Arboleda, 1990:115). Se cree que el principal motivo de su viaje lo produjo el statu quo en los diferentes estados, provincias y ciudades de la república, escenarios continuos de enfrentamientos civiles a lo largo del siglo XIX. Durante su estadía en Europa, Reed adquirió los conocimientos de la arquitectura penitenciaria al tener contacto con la obra del filántropo inglés John Howard -El Estado de las Prisiones en Inglaterra y Gales-, publicada por primera vez en 1777. Inventario que reúne las experiencias vividas directamente por Howard, en su trabajo como inspector de las cárceles y hospitales de finales del siglo XVIII, en países como Alemania, Inglaterra, Gales, España, Francia, Suiza, entre otros. Obra literaria que da cuenta de la administración penitenciaría en temas tan diversos como los castigos y torturas, cuotas (pagadas por los prisioneros), alimentación trabajo y disciplina, reglamentos y administración, instalaciones de unas 100 prisiones en los mencionados países. Howard describe también con detenimiento el estado de la infraestructura arquitectónica que componían estás cárceles; espacios como las habitaciones del alcalde, oficinas, almacenes, celdas, calabozos, patios, galerías, albercas, letrinas, escaleras, capillas, etc. Este inventario se convirtió en uno de los textos que Reed adoptó para llevar a cabo sus tres proyectos de presidios en Suramérica: la Penitenciaría proyectada, en 1845, en el puerto de la Guaira; la Penitenciaría para la provincia de Bogotá, en 1849; y la Penitenciaría de Quito, construida entre 1870 y 1875. 


\section{Diseño de una Penitenciaria para el Estado de Cundinamarca en 1849}

Diversas cárceles que se erigieron en el periodo colonial presentaban, a mediados del siglo XIX, un mal estado de conservación generalizado, en el territorio de la Nueva Granada. La necesidad de adecuarlas para un mejor servicio, se presentó en el Informe rendido en septiembre 15 de 1849, por parte el Gobernador de la Provincia de Bogotá, Vicente Lombana Buendía, a la Cámara de Provincia, en su reunión ordinaria:

\section{Carceles de circuito}

La Ordenanza 43 dispuso, de acuerdo con lo que sobre esto previene la Ley de 3 de junio de 1848 , orgánica del régimen municipal, que se refaccionasen las cárceles de Bogotá, Guaduas y la Mesa, que son las que lo necesitan con mas urgencia. En el número 250 del Constitucional se publicó el decreto gubernativo de 6 de noviembre anterior, dictado en ejecución de aquella Ordenanza. Sin embargo, de estas disposiciones la única cárcel en que se trabaja es en la de La Mesa. Todo lo que ha podido hacerse, respecto de las otras dos, es colectar algunas sumas insuficientes para la reforma radical que necesitan.

Pero en ninguna parte se hace sentir mas la falta de una buena cárcel que en esta ciudad, pues las que hoy llevan este nombre son mil veces peores que las que existían en tiempo del Gobierno español. Hacinados los infelices presos en un local incómodo, estrecho, insalubre y a medio construir, sufren todos los rigores del hambre, del desamparo y de la desnudez, careciendo hasta de aire respirable, como lo manifesté a los jefes políticos de este circuito judicial, en mi orden circular de 11 de agosto, inserta en el número 270 del Constitucional, al exigirles el estricto cumplimiento del decreto gubernativo citado, de 6 de noviembre de 1848. (Informe, 1849, p. 18)

Al igual que el trabajo realizado por Howard, como inspector de prisiones en diferentes países de Europa a finales del siglo XVIII, el Gobernador Lombana visitó varias cárceles en los diferentes estados de la Nueva Granada, entre ellas, en 1848, las cárceles de Bogotá. De estas edificaciones también rindió informe de la infraestructura y funcionamiento de los presidios de esta provincia, en el que recomendaba a los jueces del distrito prestar especial atención a la Ley del 18 de mayo de 1848 en la que se...

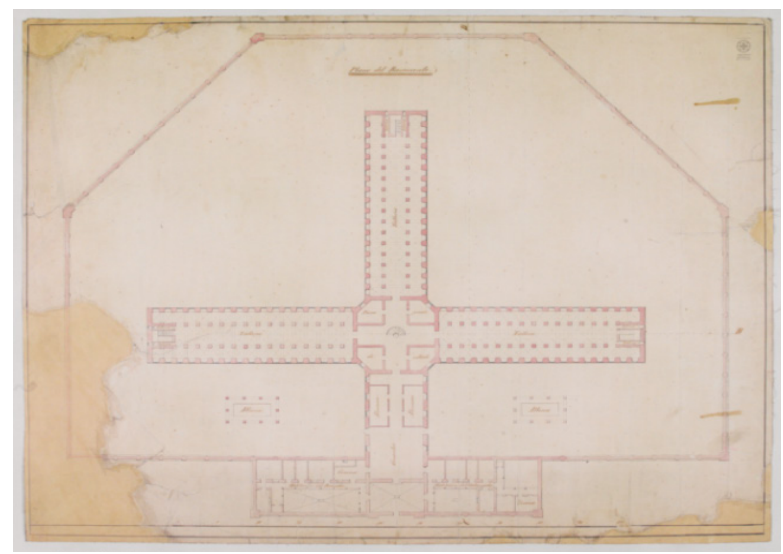

Figura 3. 1849. Penitenciaria de Bogotá. Thomas Reed. Planos originales del basamento (o primer piso). estableció el concierto de los presos por deudas menores de cincuenta pesos, y la de las disposiciones legales que ordenan que las mujeres honestas no sean reducidas a prisión por deudas, en las mismas cárceles en que se hallan otras por causas criminales. A pesar de la disminución considerable que estas medidas produjeron en el número de presos, era tal todavía la superabundancia de ellos, en la cárcel de hombres, que la Gobernación se vio en la necesidad de pasar setenta a la Casa de Refujio, para libertarlos de la muerte segura que les amenazaba, continuando allí apiñados por mas tiempo; pero siendo esta una medida transitoria, tomada para salvarlas vidas de aquellos infelices en los momentos en que se creyó que se acercaba el cólera, las cosas no pueden continuaren el estado en que se encuentran, porque la Casa de Refujio está destinada a otros objetos no menos sagrados. (Lombana, 1848, p.18).

Esta lamentable situación de hacinamiento y otras difíciles condiciones de los privados de la libertad, hicieron que se prestará especial atención a la necesidad de diseñar y construir una prisión en la provincia de Bogotá. Para ello, el mencionado informe decía:

El arquitecto, Sr. Tomas Reed, ha trabajado el plano de un vasto edificio que satisfaría completamente las necesidades de la capital en este punto. Ojalá que vosotros acometieseis la ejecución de esta grande obra que exijen imperiosamente las circunstancias. Verdad es que será muy costosa; pero para llevarla a efecto no solo debe contarse con que ayudarán todos los Cabildos del circuito, sino con el producto de la venta de las cárceles que hoy existen, que son de muy fácil realización (Informe, 1849, p.18).

Según este informe, los planos se trazaron en 1849 y, sin embargo, la invitación pública que buscaba a un contratista para ejecutar la construcción de la Penitenciaría Central o de Cundinamarca se firmó cuatro años más tarde, el 9 de febrero de 1853 (Arboleda, 1980:12). Tanto los planos de la Penitenciaria trazados por Reed, como los posteriores de otros arquitectos, se encuentran salvaguardados en el Archivo General de la Nación. Dos de ellos, el del basamento (o primer piso) y el del segundo alto (o tercer piso) son dibujos de Reed, (ver Figuras 3 y 4); los demás son litografías realizadas posteriormente, sobre dibujos del arquitecto Ramón Guerra Azuola (ver Figuras 5 y 6)

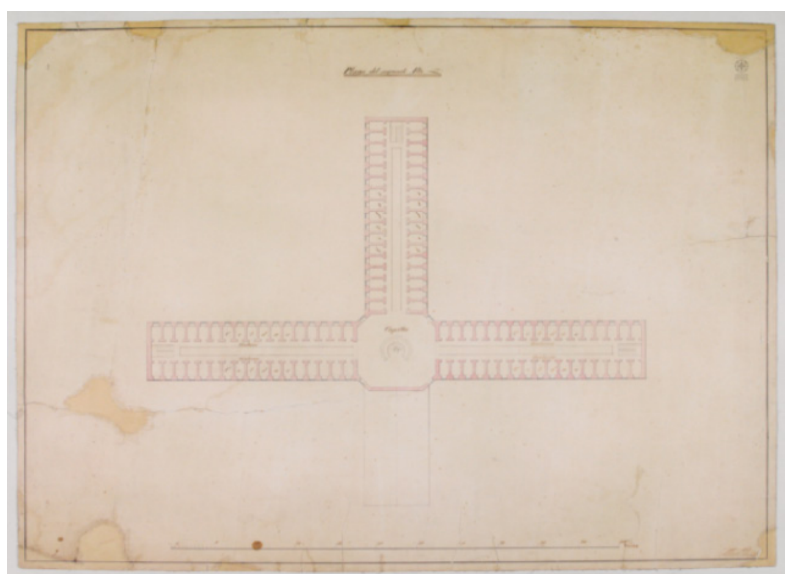

Figura 4. Plano del segundo alto (o tercer piso). Original en tinta, lápices de colores azul y rosado y crayola sobre papel.

Fuente: AGN. Mapoteca I, número. 41 1849. Estado actual. 


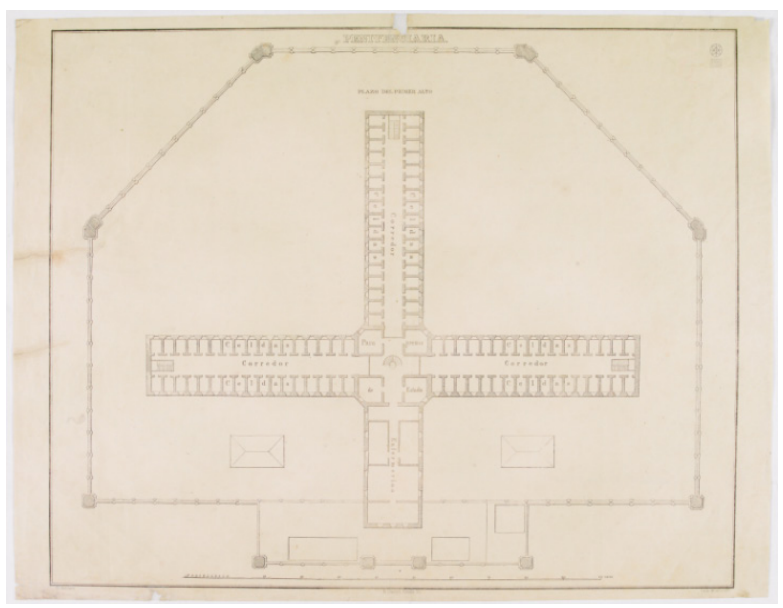

Figura 5. Thomas Reed (inv.), Ramón Guerra Azuola (dib.), Martínez Hermanos (Lit). "Penitenciaria". Plano del primer alto o segundo piso. Bogotá. ca, 1855, litografía.

Fuente: AGN. Mapoteca I, núm. 65. Fuente: AGN. Mapoteca 1, núm. 65. (dos planos).

En los planos antiguos se aprecia la traza original del edificio: un planteamiento cruciforme, con tres brazos simétricos largos y uno corto que empata con el cuerpo frontal formando una " $T$ ". Los brazos o pabellones de la cruz (también llamados en el siglo XX "rastrillos") convergen en un centro formado por un octógono irregular que surge del recorte de las esquinas de un cuadrado. En el cuerpo frontal más reducido que los pabellones de la cruz griega, se trazaron cuatro patios, uno de ellos frente al vestíbulo de llegada y dos simétricamente dispuestos a lado y lado, bordeados por estancias pertenecientes a las habitaciones del director y el proveedor de la penitenciaria, y un cuarto patio en la esquina suroriental del cuerpo central. Curiosamente en la planta del segundo piso, dibujada por Guerra Azuola, sólo se aprecian las aperturas de tres de esos patios; el ubicado frente al vestíbulo no figura. En su lugar, aparece una cubierta a tres aguas en teja de barro.

De acuerdo con estos planos, la idea de Reed consistía en localizar el presidio en los tres pabellones de la cruz, controlables parcialmente desde el centro. El primer piso de planta libre, contuvo la enfermería, letrinas y los talleres que debían destinarse a actividades comunes como el tejido de tapetes, carpintería, hilado de cuerdas, sombrerería y alpargatería; los dos pisos restantes contaron con las galerías o circulaciones, las celdas para presos de estado y celdas individuales (sin lavabos, ni inodoros). En los primeros documentos referentes a la obra, y citados por Martha Segura, se habla de penitenciaría, pero en la placa conmemorativa colocada en 1876 se lee la palabra panóptico (Segura, 1995:78) (del latín pan-todo; opticovisión). De ese año en adelante se le reconoció con este nombre, aunque en el sentido estricto del término, los tres pabellones de la penitenciaria de Reed no podían ser vigilados del todo desde el centro, pues en este espacio proyectó una escalera en forma de caracol o circular de un diámetro de 3.65 metros que ascendía hasta el tercer piso del presidio.

Hacía mediados del siglo XIX, el "vasto edificio" señalado por el gobernador Lombana, realmente era un proyecto inmenso para los estándares constructivos de la época. Se trató de una de las ideas arquitectónicas más grandes de la segunda mitad del siglo XIX en Bogotá; una obra proyectada originalmente en varas castellanas; medida que según el artículo $1^{\circ}$ de la ley de 26 de mayo de 1836 establecía que...

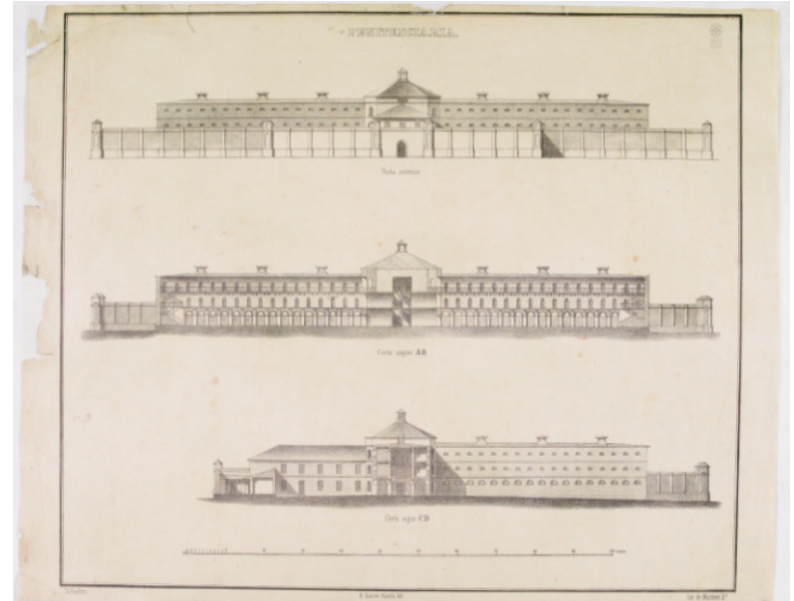

Figura 6. Penitenciaría. Vista exterior. Corte según $A B$. Corte según CD. Thomas Reed (Inv.), Ramón Guerra Azuola (Dib.). Martínez Hermanos. ca. 1855. Litografía.

Fuente: AGN. Mapoteca I, núm. 65. Fuente: AGN. Mapoteca 1, núm. 65. (dos planos).

la vara granadina será la unidad fundamental de las pesas y medidas nacionales. Considerando dividido el arco del meridiano terrestre, comprendido entre el Ecuador y el Polo, en 12.500 .000 partes iguales, una de estas partes será la vara granadina, que por lo mismo queda igual a 8 decímetros, medida francesa

El valor de la vara es aquí de $80 \mathrm{~cm}$.

Artículo $2^{\circ}$ (de la misma ley). La vara se dividirá en cuartas, cada cuarta en dos octavas, cada octava en cinco pulgadas y cada pulgada en diez líneas. Contendrá así la vara 40 pulgadas, o 40 líneas

Artículo $3^{\circ}$ Las medidas de superficie serán: la vara cuadrada, o un cuadrado con cinco varas de lado, que contiene 25 varas cuadradas (Páez, 1940, pp. 141-142).

En 1849, el arquitecto Reed llevaba tres años residiendo en Bogotá y ejerciendo los oficios de la arquitectura y su enseñanza. Como la ley citada era nacional, varios arquitectos, ingenieros, albañiles y carpinteros se sujetaron a este dictamen y proyectaron sus obras en varas castellanas. Los ejercicios de dibujo de las Figuras 9-11, ejemplifican una cuadricula que representa las medidas y equivalencias de una pulgada $=2$ centímetros, una octava $=10$ centímetros, una vara $=80$ centímetros, 100 varas $=80$ metros cuadrados, etcétera. (ver figura 7)

Todas las condiciones arquitectónicas, medidas, materiales, características técnicas y constructivas específicas para el proyecto de la Penitenciaria fueron publicadas en Bogotá en varios números de la Gaceta Oficial (Núm. 1625, 1626 y 1627). Aunque el documento no lo específica, resulta muy probable que el ingeniero Reed escribiera estás condiciones desde 1849 (fecha en que trazo los planos), pero que se publicaran por primera vez al público en general cuatro años después, en la sección de la Secretaria de Relaciones Exteriores de la Gaceta No. 1625 del 9 de noviembre de 1853. Entre otras cosas, las condiciones buscaban, en todo el territorio neogranadino, "al mejor postor" que ejecutará la totalidad de las obras de la prisión en un contrato firmado con el gobierno y en un término de ejecución de cuatro años. Es también probable que Reed no estuviera en condiciones de encargarse de este nuevo contrato, debido a que desde 1847 se encontraba en medio del proceso constructivo del Capitolio Nacional; edificio en el que hasta 1853 se habían invertido más de 200.000 pesos en tan solo los cimientos, zócalo y terraplén. 

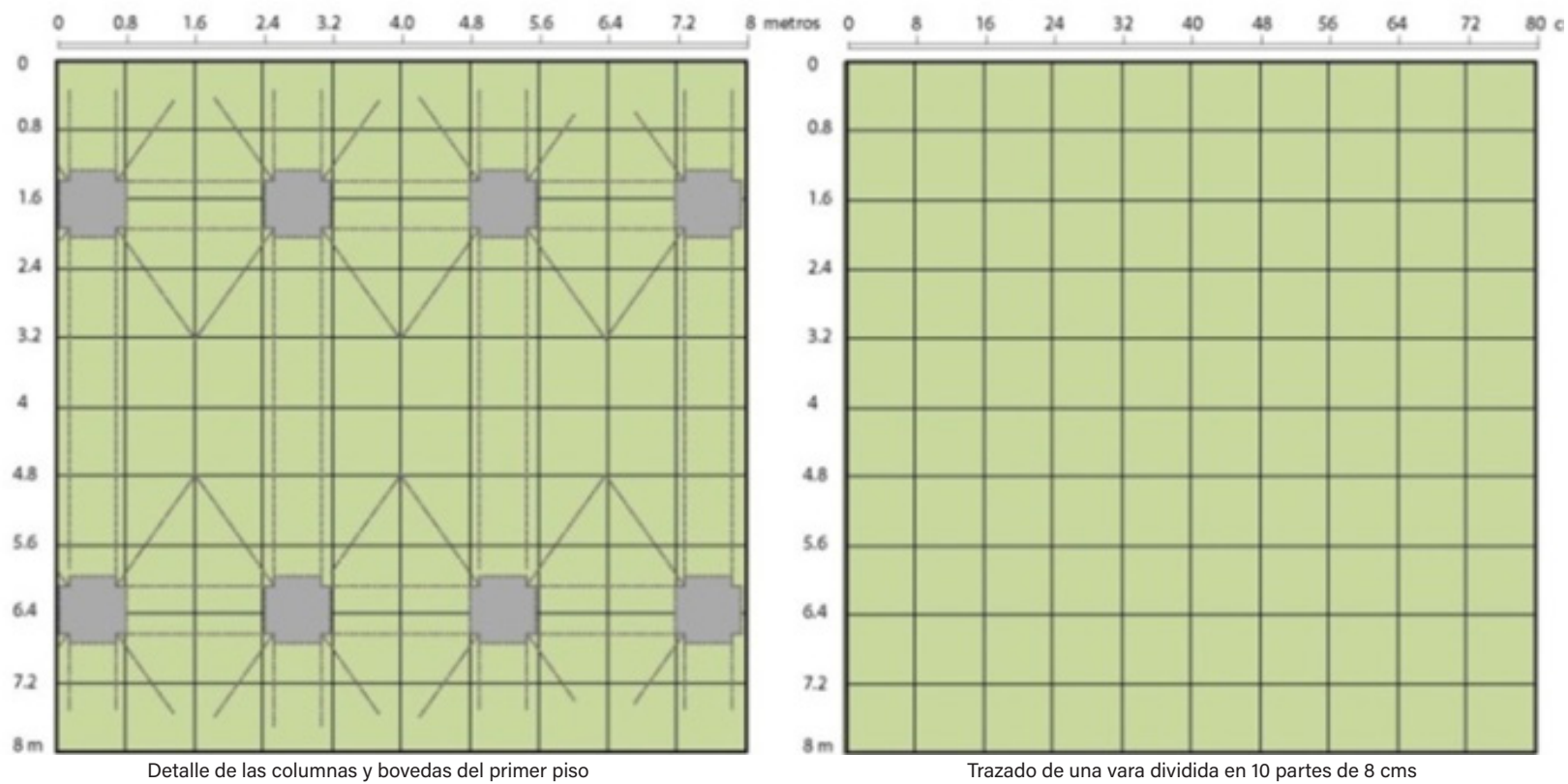

Figura 7. Representación de una vara cuadrada y de ocho varas en sistema métrico decimal.

Fuente: Dibujo del autor. 2018.

En general, la penitenciaria original fue un edilicia de planta hexagonal conformada por una muralla perimetral de cinco varas (4 metros de altura aproximadamente) construida en piedra y cal. Se desconoce si el cerramiento poligonal de la parte posterior de la prisión se erigió como lo proyectó Reed, pues no existen evidencias gráficas que lo constaten (ver Figura 8). Los cimientos generales de la penitenciaria se fundieron con un mínimo de una vara de profundidad y se rellenaron con cal y "piedra extraída de una cantera inmediata, operaciones laboriosísimas, en las cuales solamente se ha contado con el presidio, pues los gastos consistentes en pólvora, composición

Trazado en varas del espacio general de la penitenciaria

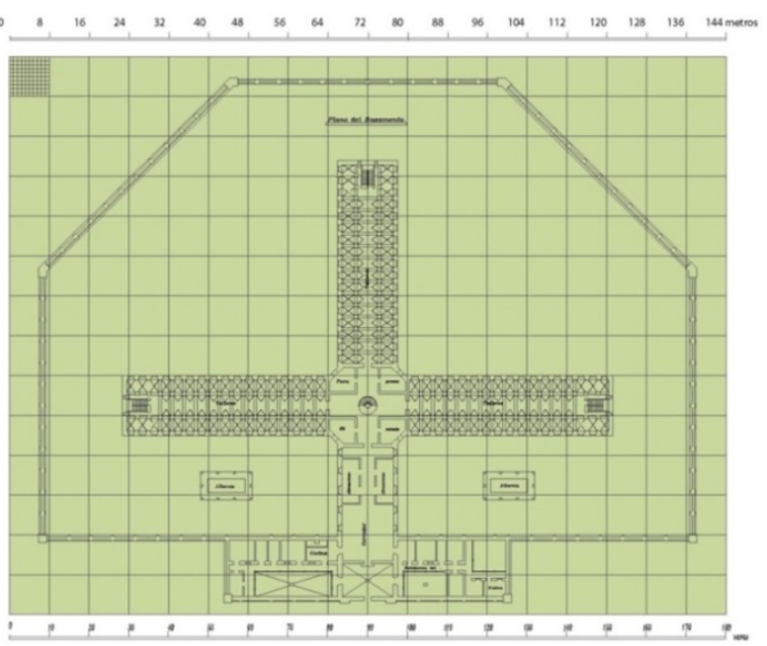

Figura 8. Penitenciaria de Bogotá superpuesta en una cuadrícula de 180 varas x 140 varas (equivalente a $144 \times 112$ metros) Dibujo del autor. 2018.

Fuente: Dibujo del Autor. 2018 de herramientas y carretillas y en el salario de un cantero libre, han sido insignificantes" (SÁENZ, 1874:63). Los cimientos de los pilares que sostenían las bóvedas de los talleres (actuales "salas donde se adelantan las obras de preservación y mantenimiento del edificio, la Sala del Museo Wiki y las salas de Obras en tránsito y reserva visible de la colección de etnografía del Museo Nacional) tuvieron el doble de ancho y se proyectaron de forma cuadrada con piedras menores de una vara de largo.

La hilada que completaba el cimiento a ras del suelo se fijó con mortero de cal y arena. Las demás piedras de los cimientos se fijaron en arcilla bien macizada con piedras pequeñas y cascajo. El mortero mencionado para los cimientos se mezcló en una proporción de una medida de cal por tres de arena limpia. En los lugares de los cimientos por donde pasaban las cañerías, se construyeron arcos de un tamaño que abrazaban las dimensiones de la misma cañería. Las paredes de los tres brazos del edificio donde se ubicaron las celdas y las del polígono de seis lados del que parten estos, se construyeron de calicanto, "procurando que las hiladas quedaran a nivel, y que las piedras que se emplearan fueran en lo posible iguales en su altura". Las piedras que formaron las superficies o caras de las paredes, fueron labradas a "punta de pico". Los arcos de las ventanas y de las puertas, arquivoltas y cornisas, se elaboraron con ladrillos (ver figuras 9 y 10).

Los pilares que sostienen las bóvedas de los talleres, se elevaron del mismo grosor como aparecen representados en el plano del primer piso, aunque de forma octogonal, y se construyeron de piedra labrada hasta la altura de dos varas (1.60 metros). Para la formación del calicanto, la mezcla del mortero se compuso en una relación de dos medidas de cal por cinco de arena limpia. Los pisos del segundo y tercer piso, correspondientes a los tres pabellones de celdas, exceptuando la parte correspondiente al corredor central, se enladrillaron con material bien cocido y amoldado, y colocados en mortero de la misma especificidad descrita arriba. Los techos de estos tres "rastrillos" se hicieron 


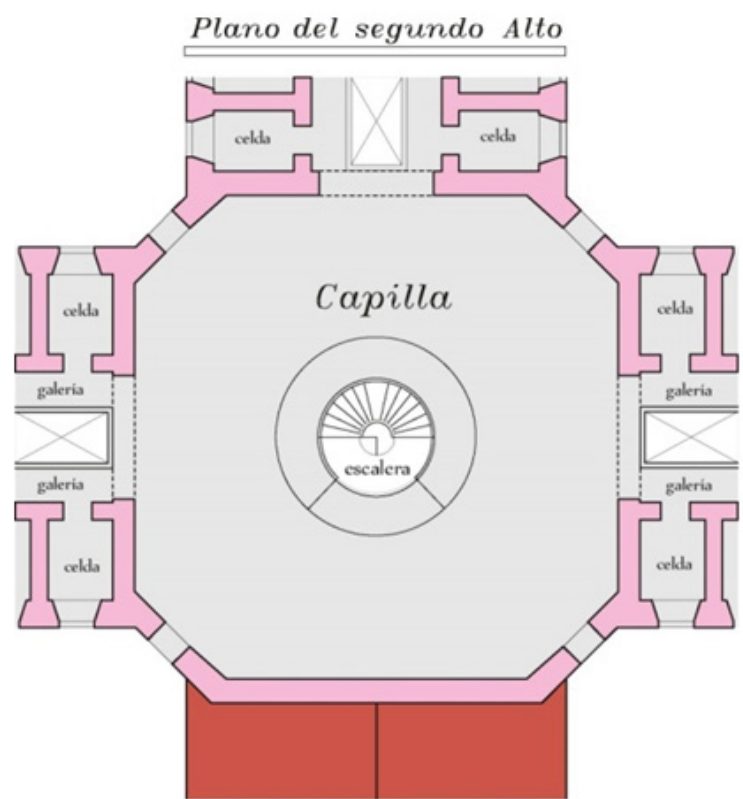

Figura 9. Capilla del tercer piso, escalera en caracol, celdas, galería o corredor y parte de la cubierta del segundo piso. Reconstrucción planimétrica del "Plano del segundo alto".

Fuente: Dibujos del autor, 2018.

de azotea, y consistieron en tres hiladas de ladrillos. En las cornisas de la penitenciaria, se construyeron canales de material cocido y vidriado para que recibieran las aguas de las azoteas, y se construyeron canales descendientes en el grueso de la pared para conducir las aguas hasta el nivel del suelo. El piso del primer piso de los tres pabellones, incluso el del polígono, se enladrillo y asfalto; asimismo el grueso de las paredes al nivel del piso (ver Figuras 11 y 12).

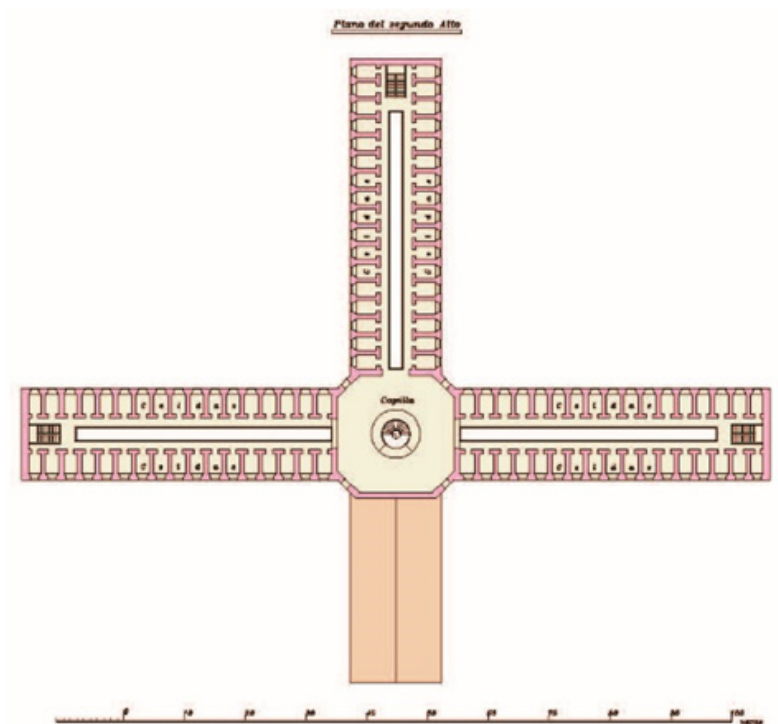

Figura 11. Reconstrucción planimétrica del "Plano del segundo alto" o tercer piso de la Penitenciaria de la Provincia de Bogotá, 1849.

Fuente: Dibujos del autor, 2018.

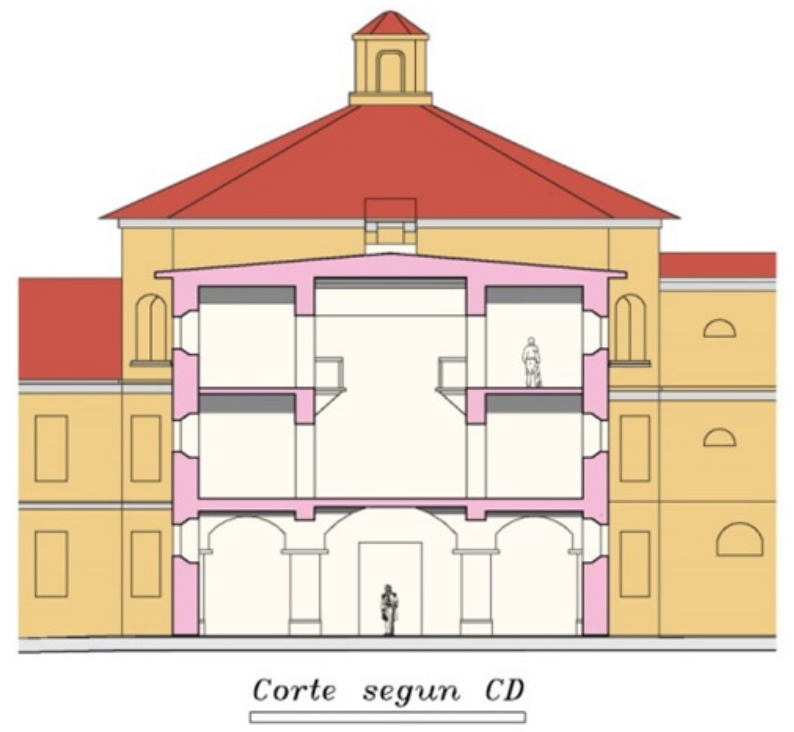

Figura 10. Corte según C-D. Detalle de los tres pisos de la penitenciaria.

Fuente: Dibujos del autor, 2018.

Las gradas de las escaleras correspondientes a los tres pabellones de celdas que conducían del primer al segundo piso se labraron de piedra; los pasamanos y barandillas se forjaron en hierro. Los espacios de las enfermerías (actuales escaleras en " $U$ " de tres tramos con descansillos) y los edificios de las habitaciones del Director y del Proveedor de la prisión (actuales Sala de Exposiciones Temporales y Auditorio Teresa Cuervo Borda) tuvieron una base de calicanto y el resto de las paredes se hicieron de adobe. Los techos de todas las edificaciones se techaron con teja de barro y su basamento se enladrillo con tablones bien cocidos y amoldados. La pared exterior de toda la "fortaleza" se trabajó de calicanto hasta la altura de tres y media varas $(2,8$ metros $)$ y lo demás de adobe.
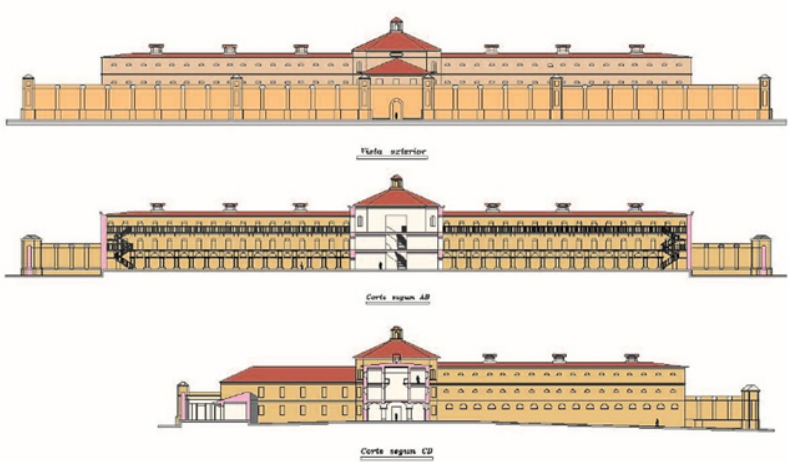

Figura 12. Reconstrucción planimétrica de la "Vista exterior" o fachada, "Corte según $A B$ " y "Corte según CD", de la Penitenciaria de Bogotá a partir del dibujo de Ramón Guerra Azuola y litografía de Martínez Hermanos.

Fuente: Dibujos del autor, 2018. 
Los bastiones angulares de la pared exterior y las laterales de la fachada se levantaron de calicanto. Las albardillas que cubrieron la pared o muralla se erigieron de dos hiladas de ladrillos de la misma clase, que se dispusieron en la azotea, es decir, puestas con "cal hidráulica" (ver figuras 13 y 14). Las dos albercas que se erigieron en los dos primeros patios de la prisión se labraron en piedra "perfectamente unidas, a prueba de agua" y tuvieron 80 centímetros de profundidad. Los pilares que sostendrían los techos que las cubren, se elevaron de ladrillo. La idea de Reed incluía que estas albercas constantemente proveyeran de agua potable corriente para ser repartida por toda la cárcel por medio de cañerías de hierro, incluyendo la habitación del Proveedor.

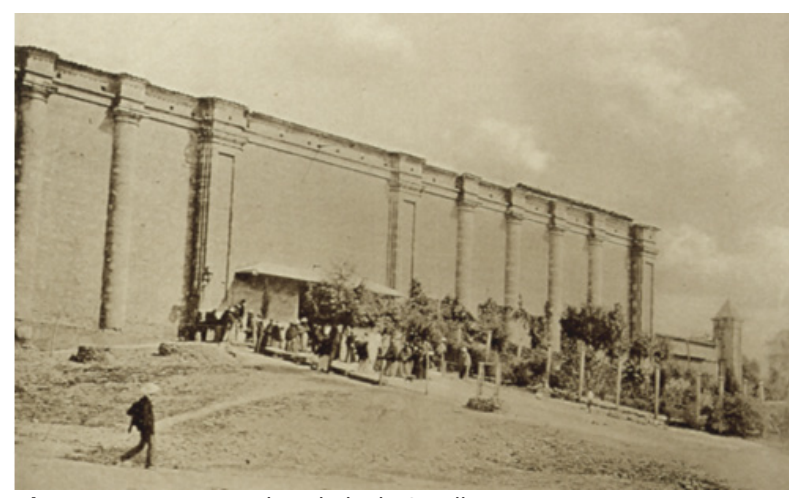

Figura 13. ca. 1905. Penitenciaria de Cundinamarca.

Fuente: Fotografía. 1905. Augusto Schimmer. Sociedad de Mejoras y Ornato.

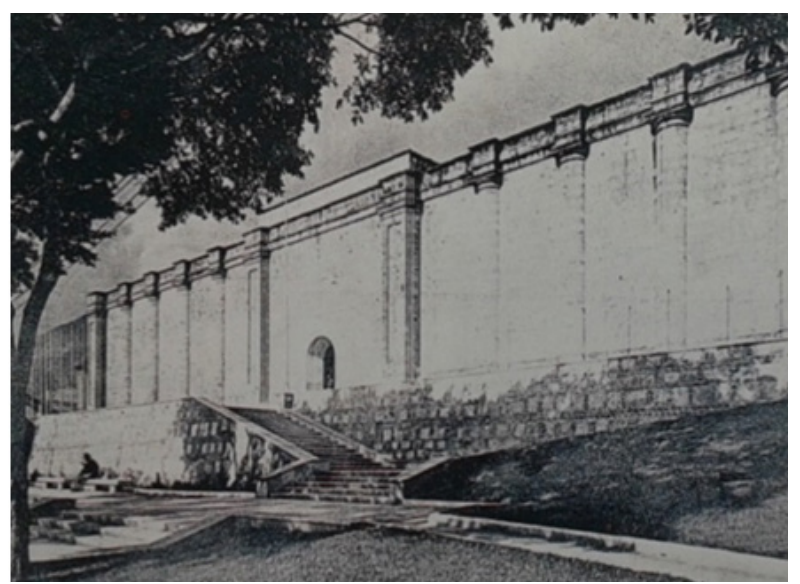

Figura 14. 1948. Anónimo. Fachada del Museo Nacional, 1948, fotografía tomada una vez concluida la adecuación de los jardines exteriores y las nuevas escaleras de acceso.

Fuente: Archivo Museo Nacional de Colombia

Como en las cercanías de este establecimiento penitenciario no había agua potable para conducirla hasta el edificio, se construyeron inicialmente aljibes con sus respectivas bombas de extracción de agua, conducida a los lugares que lo requerían por medio de las mencionadas cañerías. Las letrinas tuvieron agua corriente, transportada por cañerías de ladrillo y en proporcionada cantidad de manera que se mantuvieran aseadas. Los desagües de estás letrinas daban a las afueras de la prisión, y se labraron de ladrillo y de forma elíptica (en su sección trasversal tuvieron de 30 pulgadas en su eje mayor, y 20 en su eje menor). La parte de estos desagües hasta 12 pulgadas de altura sobre su fondo, se elaboraron con cal hidráulica. La cañería por donde corrían los desagües fuera del edificio, se hizo de calicanto de $1 / 2$ vara en cuadro, y se extendió hasta desembocar en un arroyo o quebrada. Todos los patios tuvieron las cañerías necesarias para dar curso a las aguas pluviales. A todos los cuartos, pasadizos y corredores del edificio que no tuvieron por techo una con bóveda, se les hizo un cielo raso.

Todos los sofitos de las bóvedas, arcos, las paredes y pilares que se construyeron con calicanto, se estucaron con cal y arena, y las paredes de adobe se empañetaron. Todas las paredes del edificio se blanquearon y/o "pintaron a la aguada". Los empedrados de los patios se construyeron con piedras preparadas a martillo, y las rendijas se rellenaron con cascajo menudo. Las puertas por donde se accedía a los patios, y la que daba al exterior, tuvieron quicios de piedras labradas y un escalón donde el piso lo requiso. Las columnas de los corredores de las habitaciones del Director y del Proveedor se tallaron de madera que descansaban sobre un zócalo de piedra labrada; los sardineles de estos corredores también se levantaron con piedras labradas. Los tabiques se hicieron de adobe y bajareque.

El techo del polígono central se cubrió con lámina de zinc, y las vigas y demás maderas que se emplearon en su construcción, se labraron y prepararon hasta quedar en "estado de obra limpia". Los corredores centrales de los tres brazos de celdas se cubrieron por azoteas; y las vigas empleadas se cortaron en su sección trasversal de $10 \times 6$ pulgadas, y sus centros se separaron por un espacio de 20 pulgadas. Los listones sobre los que descansan los ladrillos de la azotea, se instalaron perpendiculares a la dirección de las vigas y tuvieron 5 pulgadas de ancho, 11/4 de pulgada de grueso y $10^{\prime \prime}$ de separación: vigas y listones que se labraron con buenos acabados. Los techos de las enfermerías, las habitaciones del Director, del Proveedor y los de las dos albercas, se erigieron de la "mejor forma y construcción" de manera que pudieran soportar el peso del entejado: estos tuvieron alares o voladizos sobre canes labrados con buenos acabados. Las vigas empleadas para todos los entresuelos de madera, las de las enfermerías, las del polígono y los corredores entre las celdas, se elevaron de 9 por 6 pulgadas en la sección trasversal, y de 30 pulgadas de distancia entre uno y otro eje de viga. El piso de estos entresuelos se hizo de tablones de madera de 2 y $1 / 2$ pulgadas de grosor y un ancho que no excedió las 9 pulgadas quedando machihembrados. La parte del entresuelo de la enfermería que se proyectó sobre el local de la guardia (o vigilantes armados) se sostuvo por seis columnas de hierro de 5 pulgadas de diámetro (Ver figuras 15 y 16).

El piso de las galerías de la segunda hilera de celdas constó también de tablones de madera de la misma dimensión y del modo mencionado; sostenido por canes de madera y tornapuntas de hierro de 1 y $1 / 2$ pulgada en cuadro que se colocaron como figura en los cortes "A -B y C-D" (Ver figuras 11 y 12). Las galerías contaron con pasamanos y barandillas de hierro. Las escaleras del polígono se labraron de madera, y contaron con pasamanos y barandillas igualmente de hierro. Las escaleras que conducían del segundo al tercer piso en los bloques de celdas, se armaron también de madera, y con pasamanos y barandillas de hierro. Las ventanas de las enfermerías, las habitaciones del Director y del Proveedor, de los cuartos para "presos peligrosos", y de la Capilla, además de las hojas de madera, tuvieron bastidores con vidrieras. Todas las ventanas de la penitenciaria, a excepción de las habitaciones del Director y el Proveedor, además de las hojas de madera, contaron con rejas de hierro (cuyas varillas se cortaron de una y dos décimos de pulgada de diámetro) así como distantes 7 pulgadas entre ejes. Las rejas dispuestas en las paredes de calicanto se aseguraron enclavadas en el muro al mismo tiempo del levantamiento de estos; las demás rejas se colocaron en los marcos de las ventanas que las soportaron. Las puertas de las celdas se hicieron inicialmente de tablones 


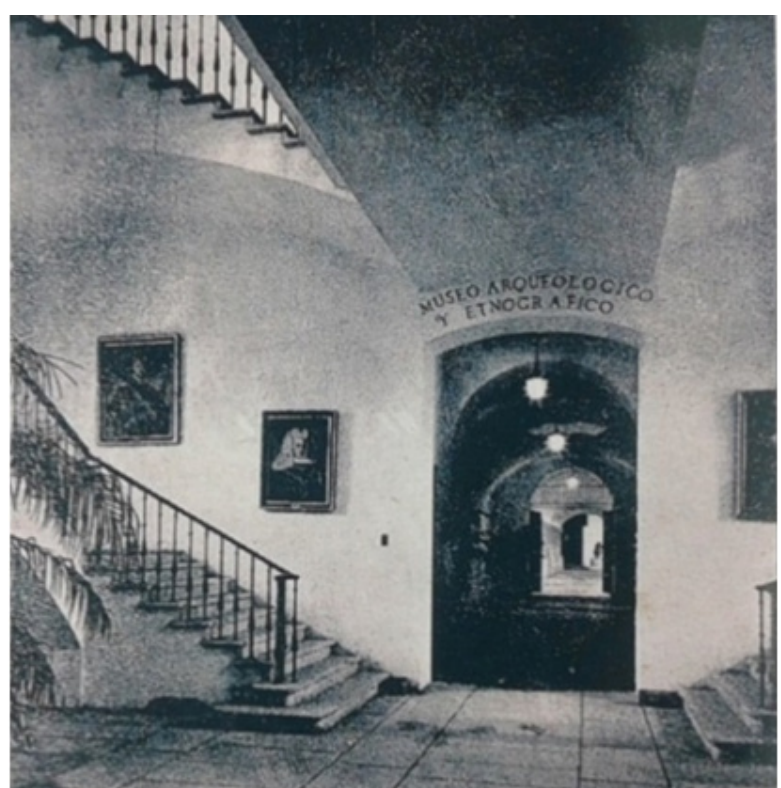

Figura 15. 1948. Anónimo. Aspecto de la exposición permanente del antiguo Museo Arqueológico y Etnográfico. Primer piso del actual Museo Nacional.

Fuente: Sociedad de Mejoras y Ornato de Bogotá.

de madera de 2 y $1 / 4$ pulgadas de grueso; cada puerta tuvo un postigo de 200 pulgadas cuadradas, con rejilla de hierro. Todas las demás puertas se hicieron de madera de muy fuerte resistencia. Las puertas que se colocaron entre las paredes de calicanto, formaron las batientes en la misma pared y los pernos sobre estribando las puertas se fundieron al mismo tiempo de ejecución de la edificación. Las claraboyas en las azoteas, se hicieron de madera de libar y la cubierta de zinc; estas tuvieron rejas de hierro y bastidores de vidrios.

Todas las puertas, ventanas y bastidores contaron con las respectivas cerrajas, cerrojos, y aldabas, para que brindaran una completa seguridad en la fortaleza (Ver figuras 17 y 18). Todas las maderas que se instalaron en la construcción de los techos y entresuelos, se cortaron con un año de antelación, y las destinadas en las demás obras, un año y medio. Los alares o voladizos de los tejados contaron con canales y tubos de zinc para recibir el agua y conducirla hasta el nivel del suelo. Todas las obras que emplearon hierro y madera, exceptuando

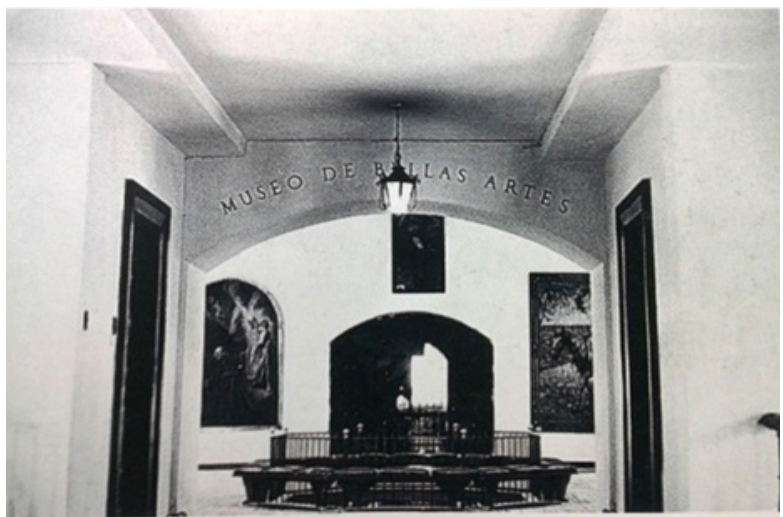

Figura 17. 1948. Anónimo. Entrada al antiguo Museo de Bellas Artes, 1948, tercer piso del actual Museo Nacional.

Fuente: Archivo Museo Nacional de Colombia 10 Procesos

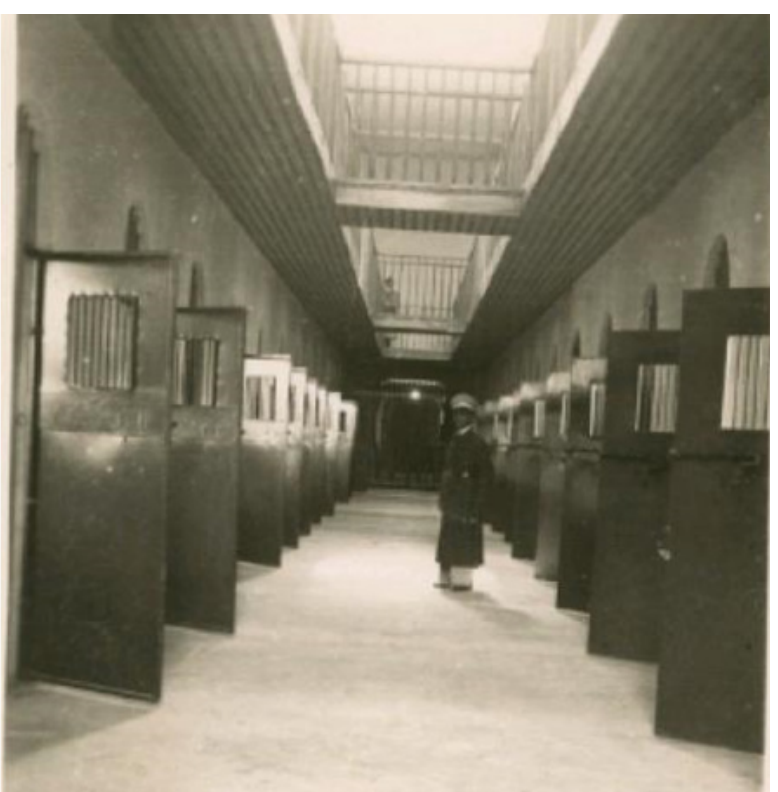

Figura 16. ca. 1941 Desconocido. Celdas de la Penitenciaría Central de Cundinamarca. (Emulsión fotográfica / Papel). Registro: $5438.026 / 101926$.

Fuente: Archivo Museo Nacional

los techos y entresuelos, recibieron tres manos de pintura de aceite. Todos los materiales que se emplearon en la obra fueron de muy buena calidad. Se contó con mano de obra cualificada (Gaceta Oficial, 1853, p. 1).

El contratista en quien se remataría el contrato estaba obligado a hacer cualquier obra que no estuviera detallada en los planos -ni especificada en el contrato-, lo mismo que cualquier modificación que pudiera darse por parte del gobierno nacional, siempre que el precio de esta no excediera los $\$ 800$ pesos y "sin lugar por parte del contratista, a exigir mayor indemnización". Igualmente, el contratista estaba obligado a someterse a la dirección e inspección del arquitecto Reed, en todo lo concerniente a la cumplida ejecución de los planos, elección y aplicación de materiales, nuevas obras, o modificaciones que se quisieran hacer por parte del gobierno. El contratista estaba obligado a terminar la construcción de la penitenciaria en un tiempo no mayor a cuatro años.

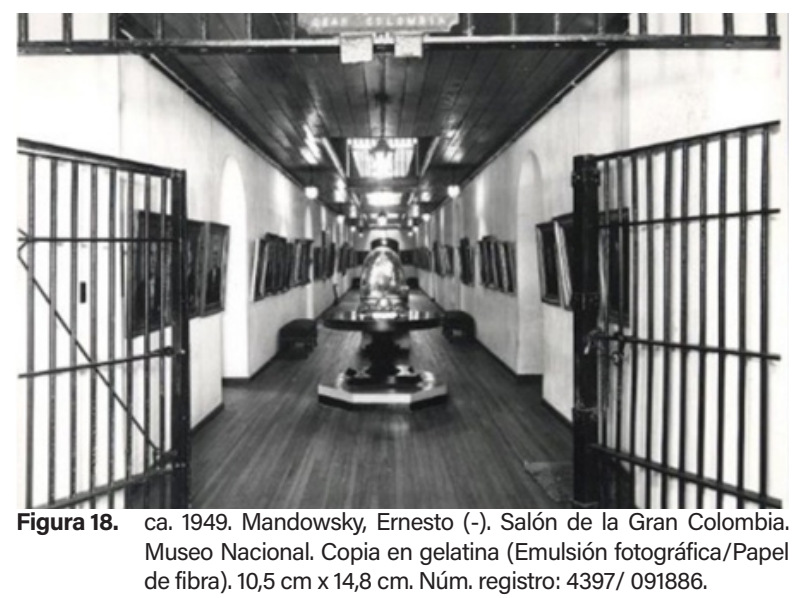

Fuente: Archivo Museo Nacional de Colombia 
Si el contratista no llegaba a entregar terminado el edificio de la prisión en el tiempo prefijado, quedaba incurso en las responsabilidades que recaían sobre él y su fiador, obligándolos a erogar la cantidad invertida hasta la completa conclusión de la obra. Por su parte, el gobierno nacional se obligaba a satisfacer al contratista una cantidad determinada de cuotas mensuales específicas hasta completar el término del contrato.

Asimismo, el gobierno debía entregar al contratista ganador de la obra el terreno idóneo para la ejecución del edificio. Solares que debían contar con la extensión suficiente para implantar las dimensiones calculadas en los planos del arquitecto Reed. El gobierno se comprometía y obligaba a dar cumplimiento del contrato, y a abonar al contratista los daños y perjuicios que se le llegaran a ocasionar por la inejecución del contrato, exceptuando en caso de guerra civil o exterior. La entrega de la obra sería verificada por el Contratista en el tiempo estipulado y, para su recepción las partes nombrarían tres peritos cada una para que reconocieran el edificio en todos sus pormenores y con el respectivo informe unánime y favorable al recibir la obra.

El Contratista debía asegurar por el término de cuatro años, contados después del recibo de la obra, la solidez y permanencia de la misma, en razón de su construcción y materiales que se hubieran empleado, y estaría obligado a "reparar a su costa cualquier defecto o daño que pudiera sobrevenir al edificio por tales motivos, exceptuando los casos fortuitos de terremoto, inundación e incendio." (Gaceta Oficial, 1853, p. 1).

Una vez trascurridos los cuatro años prefijados en la cláusula de cumplimiento, tanto el contratista como sus fiadores quedarían libres de toda responsabilidad. El contrato no quedaba definitivamente concluido hasta que no fuera aprobado por el Poder Ejecutivo. Luego de ser aprobado comenzarían a correr los plazos prefinidos en este, y se otorgarían las correspondientes escrituras, tanto para su constancia, como para las fianzas señaladas que debían prestarse. Los empresarios que se postularan para acometer la obra de la penitenciaria, lo podían hacer presentando el proyecto para ser ejecutado bien fuera en la localidad de Ocaña o en Bogotá, sobre cuyas localidades se habían "pulido informes" al ingeniero Reed. Las propuestas se debían presentar de manera separada, especificando el tiempo y el precio en el caso de construirse la prisión en cada destino. Una vez examinadas las propuestas, el Gobierno adoptaría la que considerara más ventajosa a la república (Gaceta Oficial, 1853. p. 1)

En la tabla de áreas No. 1 se identifican los diferentes espacios descritos por el arquitecto Reed en los términos para el contrato de la penitenciaria, usos y cálculos en metros cuadrados. Este cuadro nos permite construir una idea general de los lugares que compusieron la prisión original que en términos generales se diseñaron para el trabajo (talleres y almacenes), el aislamiento individual (celdas para presos comunes y de estado) y la oración (la capilla del tercer piso).

A finales de marzo de 1853, el secretario de Relaciones Exteriores del gobierno nacional rendía informe al congreso de la república en el que daba a conocer el provecho que se obtendría con la materialización del proyecto de la penitenciaria (o Casa de Castigo) en la provincia de Bogotá, entre los cuales se buscaba asegurar que los delincuentes fueran castigados y se continuara avanzando en las medidas que el gobierno adelantaba en procura de alcanzar la abolición de la pena de muerte en todo el territorio nacional. El edificio penitenciario de Reed, gestado durante la administración del general Cipriano de Mosquera, era una idea producto del pensamiento liberal que año tras año, desde 1849, había encontrado varios impedimentos que obstaculizaban su anhelada ejecución:

[...] Entre los edificios cuya construcción puede hacer honor a una Nación, sin duda que el de una Penitenciaría es tal vez el más notable, por el provecho inmediato que hace reportar, con el castigo seguro de los delincuentes, aparte de otras mil consideraciones de utilidad general, y con la facilidad que proporciona para eliminar la pena de muerte. Es tal la popularidad que este último humanitario principio va ganando en nuestro país, y que el Gobierno se complace altamente en propagar, que espera que vosotros acordareis lo conveniente a fin de que pueda plantearse entre nosotros, facilitando el establecimiento de una Casa de castigo del indicado carácter, para que la reforma pueda decretarse cuanto antes, y llevarse a la práctica sin inconveniente para la sociedad, como lo habría necesariamente en todo caso en que se procediese sin aquella operación previa. Vuestra filantropía y vuestro liberalismo, demasiado conocidos, no permiten dudarle que haréis cuanto os sea posible para realizar este bello pensamiento. En las sesiones de 1852 quedó pendiente un proyecto de ley que daba al Poder Ejecutivo las autorizaciones convenientes en la materia. Sin un acto semejante no se podrá conseguir la posesión de una Penitenciaria con la impaciente premura que lo demanda el espíritu público del país. La actual ley vigente ha encontrado para su ejecución tropiezos insuperables, como se os informó desde 1852 (Gaceta Oficial, 1853, p. 235).

\section{El solar de los Padres de San Diego donde se erigió la} penitenciaria

En septiembre de 1862, a trece años de proyectado el plano para la penitenciaria del Estado de Cundinamarca, el Alcalde del cuartel de las Nieves, José Cenón Padilla Rico (1817-1871) posteriormente Jefe Municipal de Bogotá entre 1864 y 1865 y conocido como "Chino", levantó un plano de los solares de los padres de la comunidad religiosa de San Diego y una carnicería que existía en el extremo suroriental de la primera sección del predio (Ver figuras 19 y 20). Para entonces, los solares e inmueble habían sido desamortizados y se disponían a ser rematados. Doce años más tarde se iniciaron allí las primeras obras del edificio.

Como se aprecia en el plano hipótesis del lugar que ocupó la penitenciaria de la provincia de Bogotá en los solares de los padres de San Diego (...)" de 1862, es probable que el edificio ocupara buena parte del "primer sector" de este solar que abarcaba de norte a sur entre las calles $2^{\mathrm{a}}$ y $3^{\mathrm{a}}$ e incluyendo parte del solar con la antigua carnicería en un área aproximada de 430 m2. La segunda sección del solar que también perteneció a los sacerdotes de San Diego, tenía un área de $1.394 \mathrm{~m} 2$, sin incluir la carnicería, y comprendía el área entre la Calle 10 o "Carrera Jamesa" y la Calle 12 o "Carrera de Vélez" y entre la Calle $2^{\mathrm{a}}$ o "Carrera de Mosquitero" y calle 3 a o "Calle Maturin". Como se mencionó atrás, el proyecto de Reed ocupó un área total de $1.382 \mathrm{~m} 2$ aproximadamente, espacio bastante similar al área del solar del segundo sector de los padres de San Diego de 1.394 $\mathrm{m} 2$.

Debieron pasar 10 años más para que se retomara nuevamente el asunto de la construcción de una "nueva" penitenciaría en la ciudad de Bogotá. Y solo hasta el 18 de julio de 1872, le es encargada está misión a Carlos Sáenz. Al respecto, señala Juan Felipe García que entre los años 1871 y 1872, existió un viejo local llamado San Buenaventura anexo al extinguido convento de San 
Procesos Urbanos N 5 Enero - Diciembre; 2018. ISSNe: 2500-5200

Tabla 1. Espacios y cuadro de áreas de la penitenciaria de Bogotá, 1849

\begin{tabular}{|c|c|c|c|}
\hline Título - espacio & Uso & área privada & área construida \\
\hline & Plano del primer piso o basamento & & \\
\hline alberca & $\begin{array}{l}\text { A manera de pozo estuvo cubierta por una techumbre a cuatro aguas ( } y \text { teja de barro) } \\
\text { con estructura en madera. }\end{array}$ & $\begin{array}{l}58 \mathrm{~m}^{2} \\
\text { área de la cubierta }\end{array}$ & $\begin{array}{l}20.44 \mathrm{~m}^{2} \\
\text { área del pozo }\end{array}$ \\
\hline almacenes & $\begin{array}{l}\text { Espacio donde se almacenaban herramientas, documentación, papelería, algunos } \\
\text { productos alimenticios, dotaciones de los guardias, etc. }\end{array}$ & $30.26 \mathrm{~m}^{2}$ & $43.15 \mathrm{~m}^{2}$ \\
\hline Guardia & $\begin{array}{l}\text { Punto de control por parte de los guardias, pues era el espacio por donde salían también } \\
\text { los presos hacía los patios de recreo en direcciones sur y norte. }\end{array}$ & $117 \mathrm{~m}^{2}$ & $147.37 \mathrm{~m}^{2}$ \\
\hline $\begin{array}{l}\text { Habitación del } \\
\text { proveedor }\end{array}$ & $\begin{array}{l}\text { Espacios que ocupaba el empleado que suministraba las provisiones que requería el } \\
\text { funcionamiento de la prisión }\end{array}$ & $42 \mathrm{~m}^{2}$ & $58.6 \mathrm{~m}^{2}$ \\
\hline $\begin{array}{l}\text { Celdas para presos de } \\
\text { Estado }\end{array}$ & $\begin{array}{l}\text { Fueron las celdas donde el gobierno que ejercía el poder en la nación, retuvo de manera } \\
\text { aislada a los prisioneros de estado en celdas } 4,5 \text { veces más grandes que las celdas } \\
\text { "comunes". }\end{array}$ & $21.28 \mathrm{~m}^{2}$ & $34.64 \mathrm{~m}^{2}$ \\
\hline Letrinas & $\begin{array}{l}\text { Los espacios donde los prisioneros hacían sus necesidades fisiológicas. Un espacio } \\
\text { bastante estrecho de apenas una vara de ancho por } 4 \text { metros de largo, incluyendo los } \\
\text { actualmente llamados inodoros. }\end{array}$ & $3.34 \mathrm{~m}^{2}$ & $6.77 \mathrm{~m}^{2}$ \\
\hline Talleres & $\begin{array}{l}\text { Los espacios donde trabajaban los presos fabricando cabuya, muebles en madera, } \\
\text { tejiendo tapetes en telares, fabricando objetos metalúrgicos, etc. Los talleres de cada uno } \\
\text { de los brazos de la penitenciaria tuvieron un área } 387 \mathrm{~m} 2\end{array}$ & $1.160 \mathrm{~m}^{2}$ & $1.444 \mathrm{~m}^{2}$ \\
\hline $\begin{array}{l}\text { Habitación del } \\
\text { Gobernador }\end{array}$ & $\begin{array}{l}\text { Espacios que ocupaba el Alcalde o Gobernador -máxima autoridad de la penitenciaria- } \\
\text { durante sus momentos de estadía }\end{array}$ & $56 \mathrm{~m}^{2}$ & $80.7 \mathrm{~m}^{2}$ \\
\hline Cocina 1 & Cocina independiente para uso del Gobernador o Alcalde de la penitenciaria & $13.9 \mathrm{~m}^{2}$ & $23 \mathrm{~m}^{2}$ \\
\hline Cocina 2 & $\begin{array}{l}\text { Cocina donde se preparaban los alimentos para el proveedor, los guardias y todos los } \\
\text { prisioneros. Contó con una chimenea o buitrón para la extracción del humo de la estufa }\end{array}$ & $26.5 \mathrm{~m}^{2}$ & $41.5 \mathrm{~m}^{2}$ \\
\hline área de recreo -"jardines" & $\begin{array}{l}\text { „El espacio más grande de la penitenciaria donde los presos hacían ejercicios, gimnasia, o } \\
\text { realizaban juegos entre compañeros }\end{array}$ & $8.309 \mathrm{~m}^{2}$ & \\
\hline $\begin{array}{l}\text { AREA TOTAL PRIMER } \\
\text { PISO }\end{array}$ & $\begin{array}{l}\text { El espacio general de la penitenciaria, incluyendo los cuatro brazos del edificio y el } \\
\text { volumen general rectangular del acceso }\end{array}$ & & $2.810,6 . \mathrm{m}^{2}$ \\
\hline \multirow[t]{2}{*}{$\begin{array}{l}\text { AREA TOTAL PRIMER } \\
\text { PISO }\end{array}$} & $\begin{array}{l}\text { El área general incluyendo la muralla y paredes exteriores de todo el conjunto } \\
\text { arquitectónico }\end{array}$ & & $11.489 \mathrm{~m}^{2}$ \\
\hline & Plano del segundo piso o primer alto & & \\
\hline Enfermerías & $\begin{array}{l}\text { Los espacios destinados a la atención médica de cualquiera de las personas que residieron } \\
\text { en la prisión (directores, proveedores, personal administrativo, presos, etc., ) que pudieran } \\
\text { presentar alguna dolencia, accidente de trabajo, enfermedad, etcétera. }\end{array}$ & $1.160 \mathrm{~m}^{2}$ & $1.444 \mathrm{~m}^{2}$ \\
\hline corredor & $\begin{array}{l}\text { Espacios de circulación a la salida de las celdas que era recorrida por los guardias y } \\
\text { prisioneros en cada uno de los pabellones }\end{array}$ & $56 \mathrm{~m}^{2}$ & $80.7 \mathrm{~m}^{2}$ \\
\hline celdas & $\begin{array}{l}\text { Dormitorio o habitación para los reclusos, sin sanitario, lavabo, ni ducha individual. La } \\
\text { penitenciaria conto con } 4 \text { celdas para presos de estado en el primer piso; } 102 \text { celdas en el } \\
\text { segundo piso, más } 4 \text { celdas para presos de estado. En el tercer piso contó con } 102 \text { celdas } \\
\text { para un total de } 212 \text { celdas en todo el edificio. }\end{array}$ & $4.66 \mathrm{~m}^{2}$ & $5 \mathrm{~m}^{2}$ \\
\hline $\begin{array}{l}\text { Celdas para presos de } \\
\text { Estado }\end{array}$ & $\begin{array}{l}\text { Fueron las celdas donde el gobierno que ejercía el poder en la nación, retuvo de manera } \\
\text { aislada a los prisioneros de estado en celdas } 4,5 \text { veces más grandes que las celdas } \\
\text { "comunes". La penitenciaria contó con } 4 \text { en el primer piso y } 4 \text { en el segundo nivel para } \\
\text { un total de ocho. }\end{array}$ & $21.28 \mathrm{~m}^{2}$ & $34.64 \mathrm{~m}^{2}$ \\
\hline \multirow[t]{2}{*}{$\begin{array}{l}\text { AREA TOTAL SEGUNDO } \\
\text { PISO }\end{array}$} & $\begin{array}{l}\text { El espacio general del segundo piso (o primer alto), incluyendo los tres brazos de las } \\
\text { celdas, las dos enfermerías y las cuatro celdas para presos de estado, corredores y } \\
\text { escaleras. }\end{array}$ & & $2.028 .46 \mathrm{~m}^{2}$ \\
\hline & Plano del tercer piso o segundo alto & & \\
\hline Capilla & $\begin{array}{l}\text { El espacio religioso que contó con un altar con cinco imágenes de santos y un Cristo } \\
\text { central. Allí oraban o se oficiaban homilías. }\end{array}$ & $219,4 \mathrm{~m}^{2}$ & $265,6 \mathrm{~m}^{2}$ \\
\hline Celdas & $\begin{array}{l}\text { Dormitorio o habitación para los reclusos, sin sanitario, lavabo, ni ducha individual. La } \\
\text { penitenciaria contó con } 102 \text { celdas en el tercer piso }\end{array}$ & $21.28 \mathrm{~m}^{2}$ & $34.64 \mathrm{~m}^{2}$ \\
\hline Galería & $\begin{array}{l}\text { Espacios de circulación a la salida de las celdas con un vano central que permitía observar } \\
\text { las celdas del segundo piso }\end{array}$ & $26.5 \mathrm{~m}^{2}$ & $41.5 \mathrm{~m}^{2}$ \\
\hline $\begin{array}{l}\text { AREA TOTAL TERCER } \\
\text { PISO }\end{array}$ & $\begin{array}{l}\text { El espacio general de la penitenciaria, incluyendo los tres brazos del edificio y el volumen } \\
\text { central octogonal de la Capilla y la escalera de acceso circular. }\end{array}$ & & $1.745 \mathrm{~m}^{2}$ \\
\hline TOTAL TRES PISOS & Área total construida de los tres pisos & & $6.584 \mathrm{~m}^{2}$ \\
\hline TOTAL & Área total incluyendo la fortaleza perimetral y el área de los tres pisos & $11.489 \mathrm{~m}^{2}$ & \\
\hline
\end{tabular}

Fuente: Elaboración propia a partir del estudio y reconstrucción en AutoCad de los planos originales del proyecto de Thomas Reed para la penitenciaria de Bogotá. AGN. Mapoteca I, Núm. 41 1849. (2018). 
Pinzón - Origen y construcción de la Penitenciaria del Estado de Cundinamarca (1849-1872).

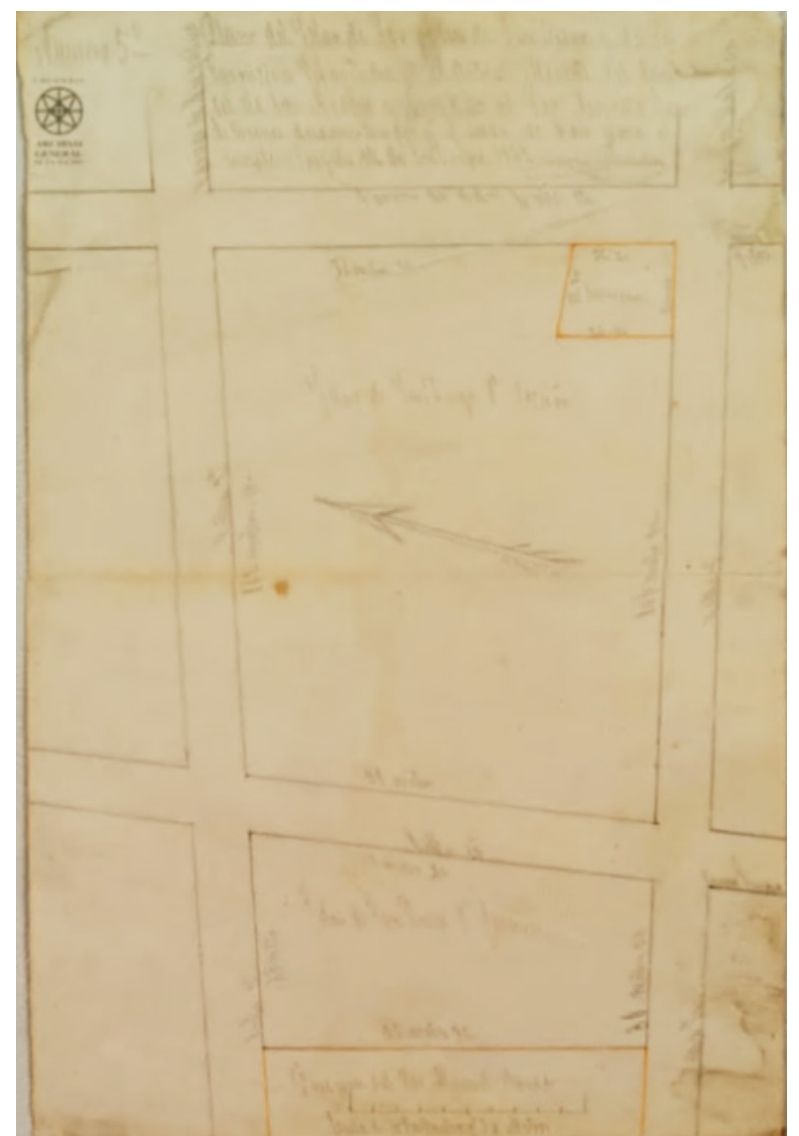

Figura 19. 1862. Cenón Padilla. "Plano del solar de los padres de San Diego y de la Carnicería Levantados por el Actual Alcalde del Cuartel de las Nieves y Remitido al Sor Agente Juez de Bienes desamortizados para que sirva de base para el Remate. Bogotá, 12 de septiembre de 1862 [rubricado]". Técnica: lápiz y tinta sobre papel.

Fuente: Archivo General de la Nación. Papel, 48 X 32 cms. MAPOTECA: SMP.4, REF.399a.

Francisco. En este espacio localizado entre las calles del antiguo "Camellón de los Cameros", actual calle 15, y entre carreras $7^{\mathrm{a}}$ y $8^{a}$, los presos se apiñaban en un espacio cuyas rejas dejaba ver la situación tan lamentable de los presos encerrados en torno a un pequeño patio (García Arboleda, 2009, sp). Ante esta situación don Carlos Sáenz., director de esta prisión (también llamada Casa de Penitencia) se dispuso a materializar el proyecto de la penitenciaría que había trazado el ingeniero Reed mientras servía durante la primera administración del General Cipriano de Mosquera. El director Sáenz obtuvo del arquitecto Ramón Guerra Azuola (1826-1903) la entrega de una reproducción que tenía de los diferentes planos para erigir la edificación carcelaria y también planteó su iniciativa al general Julio Barriga, entonces gobernador del estado de Cundinamarca. La idea fue acogida de manera entusiasta y se comisionó a Sáenz para que coordinara los inicios de la fábrica. Para entonces, el presidente Manuel Murillo Toro intervino en la iniciativa con la consecución del solar donde comenzar las obras.

Seguidamente, por medio de la Ley 11 del 12 de marzo de 1873, el Congreso de los Estados Unidos de Colombia realizó la cesión del terreno en el cual se construiría la penitenciaría. Meses más tarde y como se puede observar en la placa tallada en piedra y fijada en la fachada sur del Museo Nacional de Colombia "EL $1^{\circ}$ DE OCTUBRE DE 1874 EUSTORGIO SALGAR GOBERNADOR DE CUNDINAMARCA COLOCÓ ESTA PRIMERA PIEDRA"

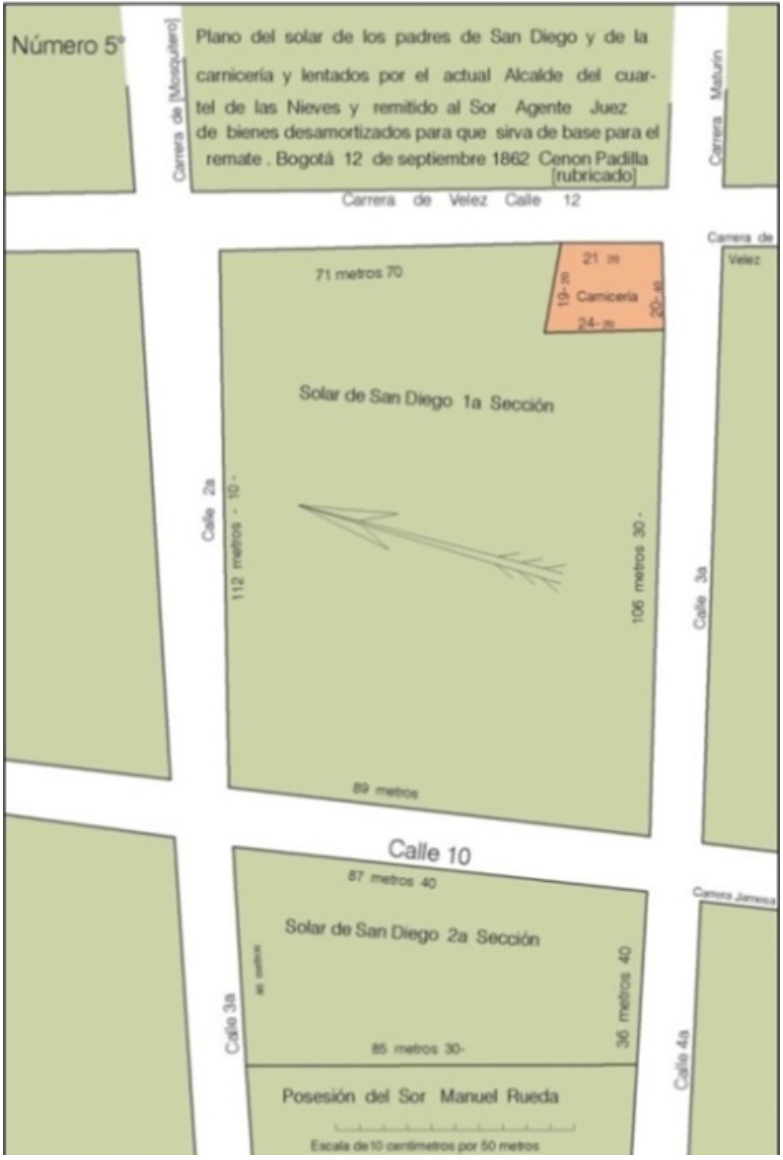

Figura 20. Reconstrucción planimétrica del plano.

Fuente: Dibujo del autor, 2018.

\section{La conversión de la penitenciaría de Bogotá en un museo}

Durante espacio de setenta años, la penitenciaría de la provincia de Bogotá funcionó para la finalidad de su diseño y erección. Entre su inauguración en 1876 y su cambio de uso en 1946 contuvo a miles de recluidos por diversas causas condenatorias provenientes de varios lugares de la geografía colombiana. En sus patios y durante muchos años se solía celebrar el día del trabajo (el primer día del mes de mayo, como en muchos lugares

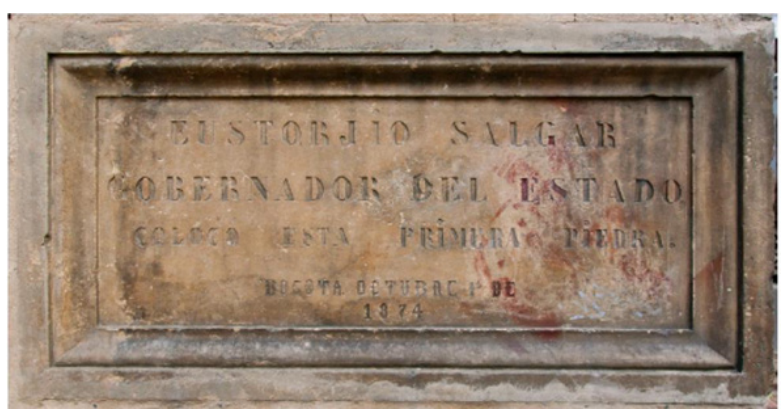

Figura 21. 1874. octubre $1^{\circ}$. Autor desconocido (-). "Placa de la primera piedra colocada al iniciar la construcción del Panóptico" Tallado por percusión y pulido (Piedra). Dimensiones: 47,8 cm x 97 cm. Núm. registro: 3595/ 091077.

Fuente: Archivo del Museo Nacional de Colombia 


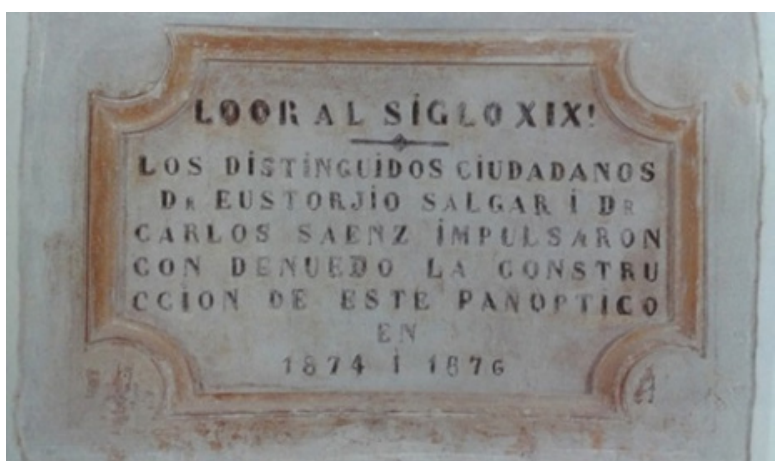

Figura 22. "Placa conmemorativa, interior ala sur, primer piso, Museo Nacional de Colombia. Registro: 3683.

Fuente: Archivo del Museo Nacional de Colombia.

del mundo). Se trataba de especiales almuerzos que eran obsequiados a todos los presos por parte de grupos de damas voluntarias de la sociedad capitalina o grupos de caridad de la ciudad (Ver figura 23). También en los patios donde actualmente circulan o se recrean los estudiantes del Colegio Mayor de Cundinamarca, los presos sembraron frutales, hortalizas y árboles cuya madera se empleaba en la manufactura de elementos que requería la misma prisión, o en muebles que eran elaborados en los talleres de carpintería del primer piso.

Como testimonio del funcionamiento de la penitenciaría durante el periodo mencionado, el Museo dejó una de las celdas del segundo alto o tercer piso, sin modificaciones. Esta excelda recrea el estado "original", preservando objetos la mayoría en hierro forjado como grilletes, pasadores, clavos, cadenas, rejas y hasta dibujos murales de una ciudad y un perro, trazados en carboncillo y lápiz de color por algún prisionero hasta la fecha anónimo.

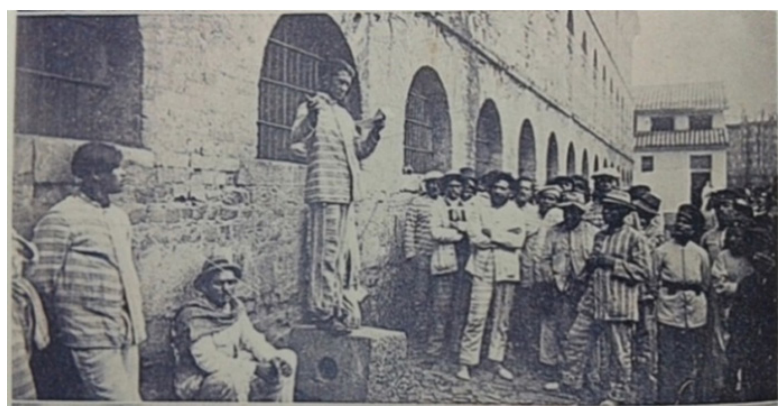

Figura 23. Uno de los presos, en nombre de sus compañeros, da las gracias por la celebración que les fue hecha el $1^{\circ}$ de mayo en el Panóptico. 1921. Anónimo.

Fuente: Revista Cromos (1921), Número. 249, 5.

Hacía 1938, algunos espacios como los talleres o "rastrillos" (como fueron renombraron por los guardias y prisioneros), se habilitaron como comedores con mesas y bancas larguísimas hechas en tabla rasa donde se sentaba a comer un preso frente a otro y bajo la vigilancia de varios guardias armados con fúsiles o bayonetas. En lugares como "la escuela", los reos recibían clases de matemáticas, español y catequismo, mientras que en algunos espacios se instalaron artefactos de castigo como el famoso "botalón" o silla grande de madera y cuero en la que se sentaba al prisionero, encadenado del cuello y los pies, permaneciendo así castigado durante horas e incluso días.
Hacía 1946, surgió la idea de demoler la penitenciaría de Bogotá (como ocurrió con la ciudad de Lima), a lo cual una de las varias personas que se opusieron a la extinción del edificio fue el bogotano Matoño Arboleda, sugiriendo que "la fábrica se utilizara como un gran museo nacional." Pero fue el entonces ministro de educación German Arciniegas, quien confirmaba en marzo del mismo año el traslado del "Museo Histórico al local donde hoy funciona el Panóptico de Bogotá". El inventario y traslado de los elementos del museo se comisionó a Hernando Rivera, jefe nacional de Educación Física del ministerio y en los primeros momentos del trasteo se realizaron proyecciones cinematográficas en el "gran salón", es decir, la antigua capilla del tercer piso del edificio (espacio que hoy hace parte de la Sala de Arte Moderno).

Dos meses después, la Asamblea de Cundinamarca aprobó el contrato a celebrar entre el gobierno colombiano y el departamento de Cundinamarca, en que se cedía a este último por el término de treinta años - prorrogables a voluntad de las partes-, los terrenos donde funcionaba el "panóptico" con el fin de instalar allíla sede del Colegio Mayor de Cultura Femenina de Cundinamarca y el Museo Nacional, y se autorizaba a la nación, realizar las adaptaciones de los espacios de la Penitenciaría Central para las "nuevas" dependencias del museo, sin que perdiera el departamento su propiedad. En el "nuevo" Colegio Mayor, el Departamento de Cundinamarca tenía derecho a la obtención de mínimo treinta becas para alumnas que eran elegidas por la Gobernación de Cundinamarca.

El traslado de los prisioneros de la Penitenciaría Central a las nuevas construcciones de la Cárcel de la Picota se efectuó a finales de 1946 (Ver figura 24). En cuanto al edificio, la fachada de la expenitenciaria se conservó y se destinaron seis meses para hacer las adecuaciones interiores del inmueble. Mientras tanto, el terreno o la propiedad del suelo continuó perteneciendo al departamento de Cundinamarca y los límites se establecieron con la edificación de mojones a manera de fuentes, columnas y monumentos.

Pasados treinta años, en 1976 expiraron las cláusulas del contrato y la nación se vio en la obligación de devolver al departamento de Cundinamarca el terreno que ocupaba toda la antigua penitenciaría, incluidas todas las mejoras materiales que se adelantaron durante las tres décadas, sin recibir ningún tipo de compensación. Esta situación es la que en la actualidad hace que el Colegio Mayor de Cundinamarca y la Universidad, no abandonen las sedes que se construyeron y los patios nororiental y suroriental que se desprenden del trazado cruciforme original del Museo (ex prisión). Como estructuras adicionales al proyecto original de Reed, se habían construido en la parte posterior u oriental de la edificación, un taller de zapatería y un comedor. Más al oriente de estos espacios estuvieron ubicadas las huertas donde los reos cultivaban productos como hortalizas para el consumo propio.

Justo antes del traslado de los presos de la Cárcel Central a la Cárcel de la Picota, el departamento de Cundinamarca tuvo que enajenar los terrenos de las huertas para que la Nación los comprara después del respectivo peritaje. Finalmente, el traslado oficial se realizó el 12 de julio de 1946 cambiando de uso por el de Colegio Mayor de Cundinamarca. Mientras tanto la directora del Museo, Teresa Cuervo fue trabajando junto con un equipo de arquitectos en las adecuaciones interiores, necesarias para convertirlo en Museo Nacional y Bellas Artes. Dos años tardaron en realizarse las reformas plasmadas en los planos del arquitecto Werner Bierman y aprobadas por el presidente Laureano Gómez. El costo alcanzó los trescientos mil pesos que fueron pagados por la Comisión Panamericana. 
Pinzón - Origen y construcción de la Penitenciaria del Estado de Cundinamarca (1849-1872).

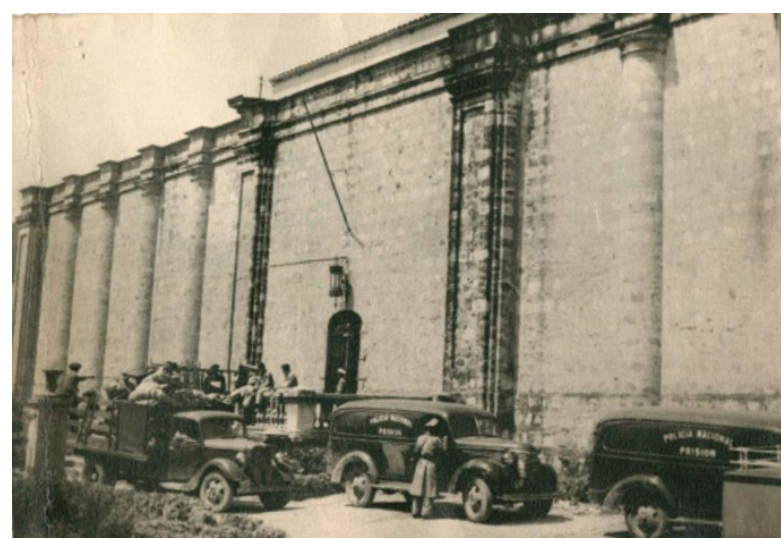

Figura 24. 1946. Agosto 12 de 1946. "Trasteo el día que el Panóptico dejó de serlo para convertirse en Museo Nacional. Gráfica de Lunga (-). Copia en gelatina (Copia en gelatina / Cartón) 10 $\mathrm{cm} \times 14$ cm. Núm. de registro 4962/ 101082.

Fuente: Archivo del Museo Nacional de Colombia

Igualmente, como crónica local, el 16 de junio de 1947 fue invitado a Bogotá el arquitecto suizo Charles-Eduard Jeanneret (reconocido como uno de los máximos representante de la arquitectura moderna y conocido como Le Corbusier), quien al pasar por la entonces carrera séptima se detuvo frente a la fachada del ahora Museo y pregunto: "Qu'est-ce que c'est?". A lo que respondieron los entusiastas arquitectos de la Universidad Nacional que lo acompañaban, que se trataba de un presidio diseñado por Thomas Reed y que estaba en proceso de transformación interna en un museo. A lo cual respondió asertivamente el señor Le Corbusier diciendo: "Gran acierto transformar un presidio en un museo" (Segura, 1995, pp. 104105).

\section{Conclusión}

El trazado de los planos para la Penitenciaria del Estado de Cundinamarca se realizaron hacía 1849 por el arquitecto Thomas Reed, quien empleó el sistema de diseño ecléctico o mixto en el que adoptó tanto elementos de la organización de los prisioneros en "aislamiento" como las condiciones del sistema de "silencio", es decir, celdas separadas para dormitorios, talleres, cuartos de instrucción, patios de ejercicios que pudieran servir en común y la imposición de un silencio más o menos riguroso. El primer contrato para la construcción de la penitenciaria de Bogotá data de 1853, pero las dificultades de orden público y económico de la república en la segunda mitad del siglo XIX provocaron el retraso de la construcción que sólo se inició en 1874, veinticinco años más tarde de su concepción inicial.

\section{Referencias}

\section{MAPAS EN ARCHIVO}

Archivo General de la Nación. Fondo: Mapas y planos. Mapoteca 1, núm. 41.

Archivo General de la Nación. Fondo: Mapas y planos. Mapoteca 1, núm. 65.

\section{ARTÍCULO EN REVISTA:}

Pradilla, Antonio M., Informe del Gobernador de Bogotá a la Cámara de provincia en su reunión ordinaria de 1849. (1849). Bogotá. Imprenta del Neo-granadino, pp. 18-19.

Informe del Gobernador de la Provincia de Bogotá entre el 18 de junio de 1849 y el 18 de diciembre del mismo año.

"Contrata para la construcción de la Penitenciaria INVITACIÓN.." (1853, Noviembre 9 ) Gaceta Oficial, (Número 1625). Secretaria de Relaciones Exteriores.

García Básalo, Alejo. (2016). Tipologías de la arquitectura penitenciaria argentina durante el siglo XIX. Revista de Historia de las Prisiones, (Núm. 2). Universidad Argentina John Kennedy / Fundación Internacional Penal y Penitenciaria. http://www.pensamiento penal. com.ar/system/files/ 2016/07/doctrina43838.pdf

Gómez de Caicedo, Patricia. Consideraciones sobre el origen tipológico del panóptico del Estado de Cundinamarca. Revista Lámpara, Vol. XXXI, (Número 122.)

Sáenz Carlos. (1874 agosto 31). Informe del Director de la Casa de Penitencia. Estados Unidos da Colombia. - Estado Soberano de Cundinamarca-Número...-Bogotá.

Revista Cromos, (1921), Número. 249, 5. 
Procesos Urbanos № 5 Enero - Diciembre; 2018. ISSNe: 2500-5200

LIBRO:

Arboleda, Gustavo, (1990), Historia contemporánea de Colombia. (Desde la disolución de la antigua República de ese nombre hasta la época presente), Bogotá, Colombia. Banco Central Hipotecario, Tomo IV y Tomo VII. 2a Ed.

García Arboleda, Juan Felipe, (2009 febrero). Regeneración o catástrofe: derecho penal mesiánico durante el siglo XIX en Colombia. Bogotá, D.C., Colombia. Editorial Pontificia Universidad Javeriana. Primera Ed: DESARROLLO EPUB: Lápiz Blanco SAS.

Howard, John (2003), El Estado de las Prisiones en Inglaterra y Gales. Primera edición en inglés, 1789. Estudio Introductorio de Sergio García Ramírez. Traducción de José Esteban Calderón. México: FCE. Fondo de Cultura Económica. Título original: The State of the Prisions in England and Wales.

Páez Courvel, Luis E. (1940), Historia de las Medidas Agrarias Antiguas. Legislación Colonial y Republicana y el Proceso de su Aplicación en las Titulaciones de tierras. Luis E. Páez Courvel de la Academia Colombiana de Historia. Estudio presentado al 2o. Congreso de Historia y Geografía de Colombia, convocado por la academia Colombina de Historia y reunido en Bogotá el 6 de mayo de 1940, en la primera conmemoración centenaria de la muerte del General Francisco de Paula Santander. Bogotá, Colombia. Editorial Librería Voluntad, S.A.

Saldarriaga Roa, Alberto; Ortiz Crespo, Alfonso y Pinzón Rivera, José Alexander, (2005). En Busca de Thomas Reed. Arquitectura y política en el siglo XIX. Bogotá, Colombia. Panamericana Formas e Impresos. Primera ed.

Saldarriaga Roa, Alberto; Pinzón Rivera, José Alexander; y Ortiz Crespo, Alfonso, (2017). En Busca de Thomas Reed. Arquitectura y política en el siglo XIX. Bogotá, Colombia. Buenos y Creativos. Instituto distrital de Patrimonio Distrital. Segunda ed.

Segura, Martha. (1995), Itinerario del Museo Nacional de Colombia 1823-1944. Tomo Il Historia de las sedes. Museo Nacional de Colombia. Bogotá, Colombia. Publicaciones Cultural. Primera ed. 